DOI: 10.20472/IAC.2019.051.028

JESSICA MURRAY

University of South Africa, South Africa

\title{
THE CASUAL CRUELTY OF FAT PHOBIA: A FEMINIST LITERARY ANALYSIS OF “UNRULY” FEMININE CORPOREALITY IN SELECTED TEXTS
}

\begin{abstract}
:
This paper explores an under researched aspect of women's lived experiences as they are represented in contemporary fiction, namely the way in which the fat female body is utilized as a trope of gendered oppression. While a great deal of medical and sociological research has been done on the purported pathology of the fat female body, scholars have been glossing over examples of extremely problematic literary representations of the corporeal intersections of fat and gender. I will argue that such fictional representations both reflect and shape popular understandings of the fat body and that these understandings are profoundly gendered and misogynist. Rather than impacting the lived experiences of only fat women, these dynamics function as a disciplinary tool that severely restricts the life choices of all women. By reading selected texts by female authors with a focus on their representations of fat female characters, this paper will demonstrate that fat has become a lazy literary shorthand for myriad, always negative, assumptions about women. I will illustrate that such examples can be found in the work of award winning female authors who have built their literary reputations as much on the quality of their writing as on their supposed insight into women's lives and psyches. When such authors use fat to denigrate female characters and that goes by without comment from scholars, we do a disservice to the millions of women who are reading these texts and receiving the message that a woman's primary responsibility continues to be to tame her "unruly" body. Fat is disruptive and a visual signal of the female body that refuses to conform to patriarchal discipline. We need to ask why this is a cause for derision rather than celebration in the work of selected female authors.
\end{abstract}

\section{Keywords:}

gender, female body, fat phobia, misogyny, women's writing 